\title{
Relationship between ignition delay time and cell size of $\mathrm{H}_{2}$-Air detonation
}

\section{Yunfeng Liu*, Wei Zhang, Zonglin Jiang}

State Key Laboratory of High Temperature Gas Dynamics, Institute of Mechanics, Chinese Academy of Sciences, Beijing 100190, China

\section{A R T I C L E I N F O}

\section{Article history:}

Received 12 December 2015

Received in revised form

27 May 2016

Accepted 4 June 2016

Available online 26 June 2016

\section{Keywords:}

$\mathrm{H}_{2}$-air detonation

Chemical reaction kinetics

Ignition delay time

Triple-shock point

\begin{abstract}
A B S T R A C T
In this paper, the coupling mechanism between shock dynamics and chemical reaction kinetics of the self-sustained propagation of $\mathrm{H}_{2}$-Air detonation was studied. Twodimensional numerical simulations were conducted and four chemical reaction kinetics models were used. The results demonstrate that the ignition delay time plays a significant role in the detonation propagation since it directly affects the detonation front structure. The longer the ignition delay time is, the bigger the cell size will be. The period of the movement of triple-wave points almost equals to ignition delay time of the reactants in the induction zone. This mechanism is very important for the hydrogen safety.
\end{abstract}

(c) 2016 Hydrogen Energy Publications LLC. Published by Elsevier Ltd. All rights reserved.

\section{Introduction}

Gaseous detonation is a supersonic self-sustained combustion wave propagating in the pre-mixed combustible gas. The leading shock front compresses the combustible gas to implement auto-ignition in a very short distance. With the help of the energy release from the combustion, detonation maintains self-sustained propagation [1]. The combustion efficiency of detonation is very high and as a result its destructiveness is also very great. Studying the mechanism of formation and propagation of detonation is very important for the prevention and treatment of coal mine gas explosion, chemical combustible gas leakage and explosion problems in industry [2-5].

The detonation front is composed of Mach stem, incident shock and transverse wave. The point where they join together is called triple-wave point. In order to theoretically explain the complex mechanism of gaseous detonation, Lee [1] proposed the SWACER (Shock Wave Amplification by Coherent Energy Release) mechanism. Jiang put forth the INWPCR (Interaction of Nonlinear Wave Propagation and Chemical Reaction) mechanism [6]. Both of these two theories point out that the essence of the detonation initiation and propagation lies in the coupling between shock dynamics and chemical reaction kinetics. If the coupling process can be broken, the detonation hazard can be prevented from happing in industry. But the key parameters controlling the coupling process is not known yet.

Extensive numerical simulations and experiments have been conducted to investigate gaseous detonation structures [7]. Oran et al. [8] studied the propagation of the $\mathrm{H}_{2}$-Air and $\mathrm{CH}_{4}$-Air detonation using one-step overall chemical reaction model. Westbrook \& Urtiew [9], Shepherd [10] and Kumar [11]

\footnotetext{
* Corresponding author.

E-mail address: liuyunfeng@imech.ac.cn (Y. Liu). 
estimated the cell size in numerical simulation using one-step overall model, respectively. In these researches, different grid sizes and computational domains were used to identify numerical requirements for high-fidelity simulations of detonation cellular structures. The effects of the pre-exponential factor, grid size, time step, domain length, and exit boundary condition on the cellular structure and cell size are examined systematically.

With recent advances in computing power, much finer grid resolutions and more complete chemical kinetics schemes have been adopted. Much information about the cellular structure was obtained, including the formation of un-reacted pockets, collision of triple-shock points, and evolution of the transverse waves [12-18]. Oran et al. [19] conducted the numerical simulation of $\mathrm{H}_{2}-\mathrm{O}_{2}-\mathrm{Ar}$ detonation using a detailed chemical reaction model. The energy release and the transverse wave are discussed in the detonation propagation. Emphasis was placed on the wave front dynamics and evolution of cellular patterns. All these attempts were made to see how the relevant parameters, i.e., the initial temperature, initial pressure, activation energy, heat release per unit mass of product species and so on, affect the cellular structures. The research showed that the activation energy $\mathrm{Ea}$ and the pre-exponential factor $\mathrm{K}$ in the mass rate of product formation are the most important parameters controlling the cellular structure. The higher the activation energy is, the unstable the cellular structure is. And the bigger the pre-exponential factor $\mathrm{K}$ is, the smaller the cell size is.

Shchelkin \& Troshin [20] first proposed that the experimentally measured detonation cell size could be correlated with the reaction zone width. Then a series of relevant studies have been done to figure out the instinct relationship between the reaction zone width and the cell size. Gavrikov et al. [21] analyzed the correlation between characteristic reaction zone widths, calculated from detailed chemical kinetic models, and experimentally measured or numerically simulated detonation cell sizes. The results showed that the characteristic reaction zone width do have a connection with the cell size. A mathematical fitting method is used to get a formula between the cell size and the characteristic reaction zone widths. Eaton et al. [22] conducted numerical simulation on the detonation cell sizes of methanol-oxygen mixtures at different initial pressures and compositions using a detailed chemical kinetic model. A similar mathematical fitting method is used to combine the characteristic reaction zone widths with the cell sizes. Taylor et al. [23] studied the dilute $\mathrm{H}_{2}-\mathrm{O}_{2}-\mathrm{Ar}$ and the $\mathrm{H}_{2}$-Air detonation using detailed chemical reaction models. Again, the mathematical fitting method is used and a formula concerning the characteristic reaction zone widths and the cell size is shown. The $\mathrm{H}_{2}-\mathrm{O}_{2}-\mathrm{Ar}$ cellular structures were regular in shape and their sizes compared reasonably well with experimental observations. However, the main mechanism in the detonation propagation is still unknown. Most of the computed $\mathrm{H}_{2}$-Air cells at atmospheric conditions are smaller than those observed in experiments. This result suggests that important physical processes are either neglected or represented incorrectly. If chemical reaction kinetics is not correct, the ignition and propagation of a detonation will be not correct.
In this paper, we studied the key coupling mechanism between shock wave and chemical reaction kinetics of $\mathrm{H}_{2}$-air detonation. We studied the ignition delay times of different $\mathrm{H}_{2}$-Air chemical reaction kinetics. And we also examined the period of triple-shock point during the propagation of detonation. The results show that the period equals to the ignition delay time quantitatively. This reveals the key mechanisms of self-sustained detonation propagation, which is very important for the detonation prevention in industry.

\section{Governing equations and chemical reaction models}

The governing equations are two-dimensional Euler equations implemented with chemical reaction kinetics. The viscous and diffusion effects are neglected. There are four detonation models used in this study, including three detailed chemical reaction models and an overall one-step Arrheniustype model. Model-1 is a nine-species, nineteen-reaction mechanism, which has modified reaction kinetics for highpressure combustion [24]. Model-2 is a nine-species, nineteen-reaction mechanism [25] and Model-3 is an elevenspecies, twenty-three-reaction mechanism [26]. Model-4 is an overall one-step model [27-29]. The governing equations and detailed reaction kinetics for these models can be found in the references.

The problem geometry is shown in Fig. 1. The detonation is propagating in a two-dimensional infinite long straight tube. It is initiated by high temperature and high pressure reactants at the left end and moves from left to right. The computational domain moves with the detonation front in order to reach the steady detonation state. The length-width ratio of the computational domain is larger than six in order to minimize the influences of boundary conditions on the detonation front. The governing equations are numerically solved using a three-order WENO scheme. The flux vector is split by Steger and Warming's method and the timemarching integration is performed using the three-order TVD Runge-Kutta integration.

In the following parts, firstly, ignition delay times of different models are studied. Then, the two-dimensional detonation cellular structures are numerically simulated with initial pressure $\mathrm{P}_{0}=0.1 \mathrm{MPa}$ and initial temperature $\mathrm{T}_{0}=300 \mathrm{~K}$. Finally, the key coupling mechanism between shock dynamics and chemical reaction kinetics is analyzed.

\section{Results and discussion}

Ignition delay time is an important characteristic time scale of chemical reaction kinetics. It's a function of temperature, pressure and equivalence ratio. There are many different ways to define the ignition delay time. In this study, the definition of ignition delay time is based on the evolution of the temperature as a function of time, $\mathrm{T}(\mathrm{t})$, and it is the time when the largest temperature changing rate (dT/dt) occurs.

According to the one-dimensional ZND model, for a steady C-J detonation, the detonation front can be divided into induction zone and heat release zone. The reactants are heated 


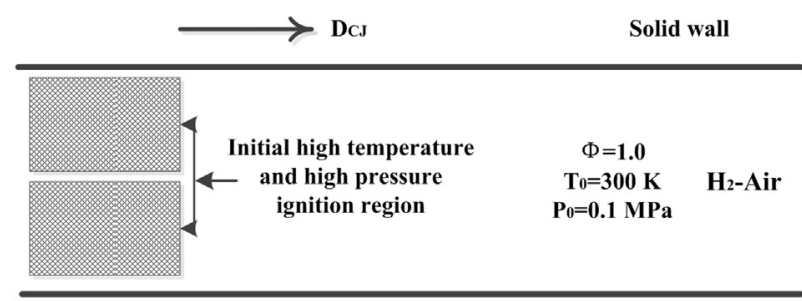

Solid wall

Fig. 1 - The problem geometry.

in the induction zone by the leading shock wave and then take chemical reaction in the heat release zone. Therefore, the thermodynamic state in the induction zone is more important for ignition delay time. According to ZND model, for the stoichiometric $\mathrm{H}_{2}$-Air detonation, when the initial pressure $\mathrm{P}_{0}=0.1 \mathrm{MPa}$ and the initial temperature $\mathrm{T}_{0}=300 \mathrm{~K}$, the Mach number of C-J detonation is $\mathrm{M}_{\mathrm{CJ}}=4.84$. And the pressure and temperature in the induction zone under the perfect gas assumption are almost $1544 \mathrm{~K}$ and $2.77 \mathrm{MPa}$, respectively. In fact, for the two-dimensional or three-dimensional cellular detonation, the temperature varies from $1300 \mathrm{~K}$ to $1500 \mathrm{~K}$ and the pressure varies from $2.0 \mathrm{MPa}$ to $3.0 \mathrm{MPa}$ in the induction zone.

Fig. 2 shows the ignition delay times predicted by the three detailed chemical reaction models as a function of the initial temperature. The initial pressures are 0.1 MPa, 1.0 MPa and 3.0 MPa, respectively. The ignition delay times at initial pressure of $0.1 \mathrm{MPa}$ are plotted in Fig. 2 (a). From this figure, we can see that the temperature region can be divided into hightemperature region and low-temperature region clearly. There is a transition-temperature of about $1000 \mathrm{~K}(10,000 /$ $\mathrm{T}=10$ ) between them. At the high temperature region, the ignition times change with temperature almost linearly under the logarithmic coordinate system. The ignition delay times of Model-2 and Model-3 are almost the same, which is about $10 \mu \mathrm{s}$ at $1500 \mathrm{~K}(10,000 / \mathrm{T}=6.67)$. The ignition delay time of Model- 1 is parallel to that of the other two models, but a little longer than them. At the low-temperature region, the ignition times become longer obviously and the difference between them becomes larger. In this paper, our attention is focused on the ignition delay times in the high-temperature region which pertains to detonation.

The ignition delay times at initial pressure of $1.0 \mathrm{MPa}$ are plotted in Fig. 2 (b). The temperature region can also be divided into high-temperature region and low-temperature region. But the transition-temperature moves to the left at a higher value of about $1300 \mathrm{~K}(10,000 / \mathrm{T}=7.69)$. The ignition delay times in the high-temperature have the same characteristics as that of $0.1 \mathrm{MPa}$. The values are one-order shorter than that of $0.1 \mathrm{MPa}$ because the ignition delay time is inversely proportional to the initial pressure at the same initial temperature. For instance, the ignition delay time at $1500 \mathrm{~K}$ is about $1 \mu \mathrm{s}$, while the ignition time of initial pressure of $0.1 \mathrm{MPa}$ at $1500 \mathrm{~K}$ is about $10 \mu \mathrm{s}$.

From Fig. 2(c) we can see that at high initial pressure of 3.0 $\mathrm{MPa}$, these three models have different transitiontemperatures. When the initial temperature is higher than $1500 \mathrm{~K}(10,000 / \mathrm{T}=6.67)$, the ignition delay times of these three

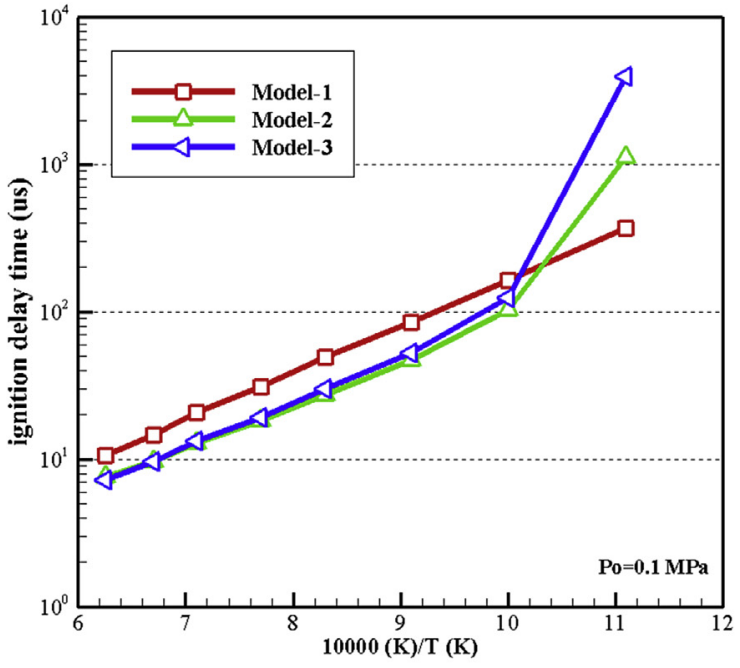

(a) $\mathrm{P}_{0}=0.1 \mathrm{MPa}$

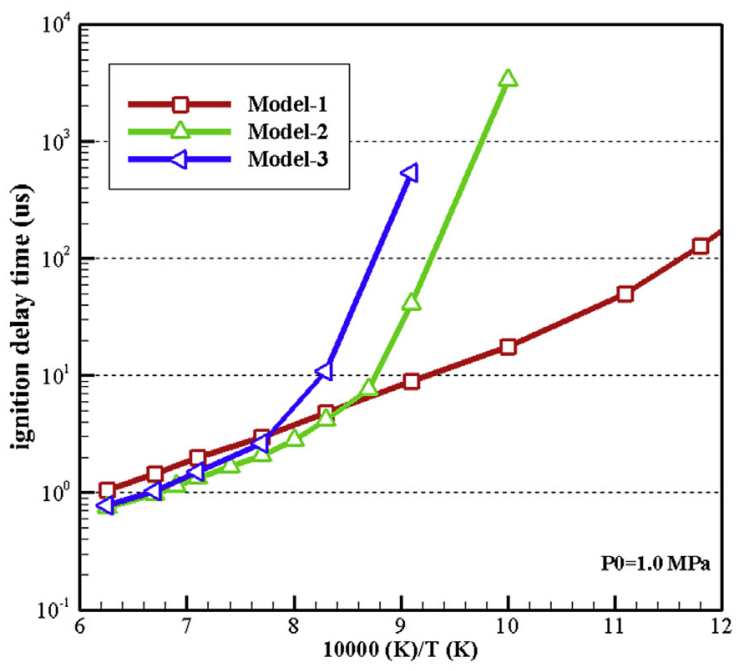

(b) $\mathrm{P}_{0}=1.0 \mathrm{MPa}$

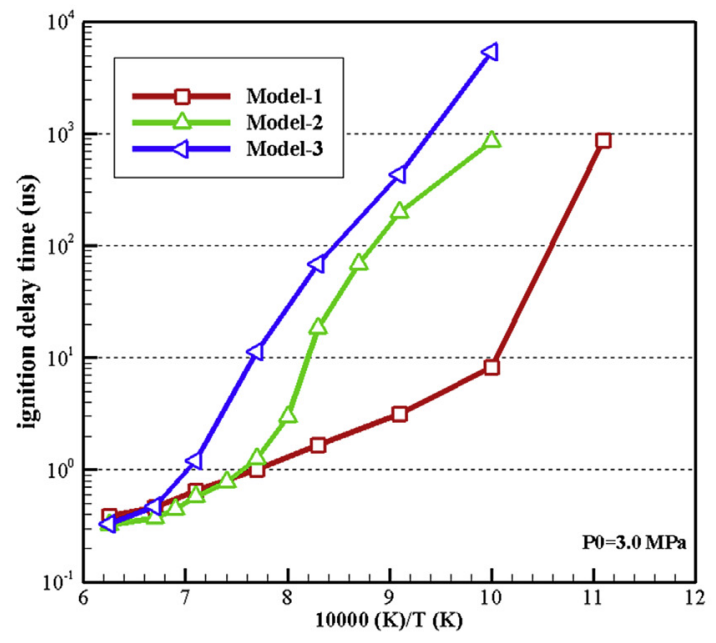

(c) $\mathrm{P}_{0}=3.0 \mathrm{MPa}$

Fig. 2 - Comparison of ignition delay times predicted by three detailed models. 
models becomes almost the same. When the initial temperature is lower than $1500 \mathrm{~K}$, the Model-2 and Model-3 have the similar trends, but Model-1 is quite different at lower temperatures because it has high-pressure modification in the chemical reaction kinetics. As a result, the ignition delay times of Model-1 at lower temperature are much shorter than that of Model-2 and Model-3.

The ignition delay times simulated by different models and the experimental results available in literature [30-32] are compared in Fig. 3. The initial pressure of numerical simulations is $0.1 \mathrm{MPa}$ and the initial pressure of experiments is $0.2 \mathrm{MPa}$. In this figure, we can find that the ignition delay times of Model-2 and Model-3 at higher temperature are close to the experimental results which mean that the numerical results are correct. The experimental results at lower temperature are less linear than that of detailed models. The slope of one-step model is larger than that of detailed models which means that it is more sensitive to initial temperatures.

The ignition delay times predicted by other detailed chemical reaction kinetic models at initial pressure of $1.0 \mathrm{MPa}$ found in literature are compared in Fig. 4. There is no experimental result because it is rare at initial high pressures. We can find that the ignition delay times are similar except Model-1 and the overall one-step model. The ignition delay time of Model-1 is much shorter than others at lower temperature because of its pressure modification. The ignition delay time of one-step model looks like a straight line. The other models have different slopes in high-temperature region and low-temperature region. At $1500 \mathrm{~K}$, the detailed models have the similar ignition delay time of about $1 \mu \mathrm{s}$, while the one-step model has the ignition delay time of about $4 \mu \mathrm{s}$.

From the above study, we also find that the one-step model has two essential differences from the detailed models. The first difference is that one-step model is a pressureindependent model and its ignition delay time does not vary

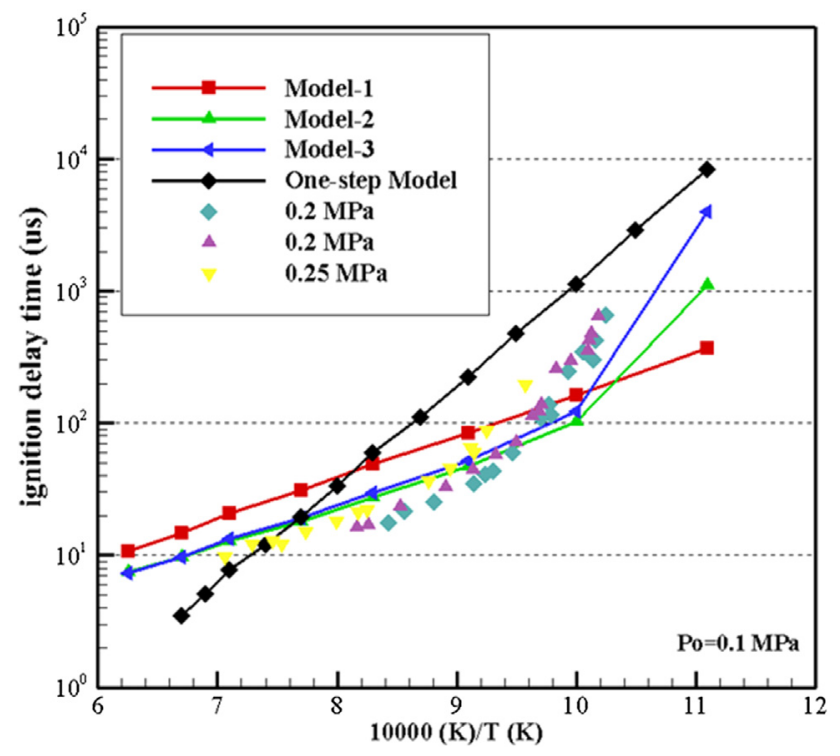

Fig. 3 - Comparison of ignition delay times predicted by numerical simulations and measured in experiments at $0.1 \mathrm{MPa}$.

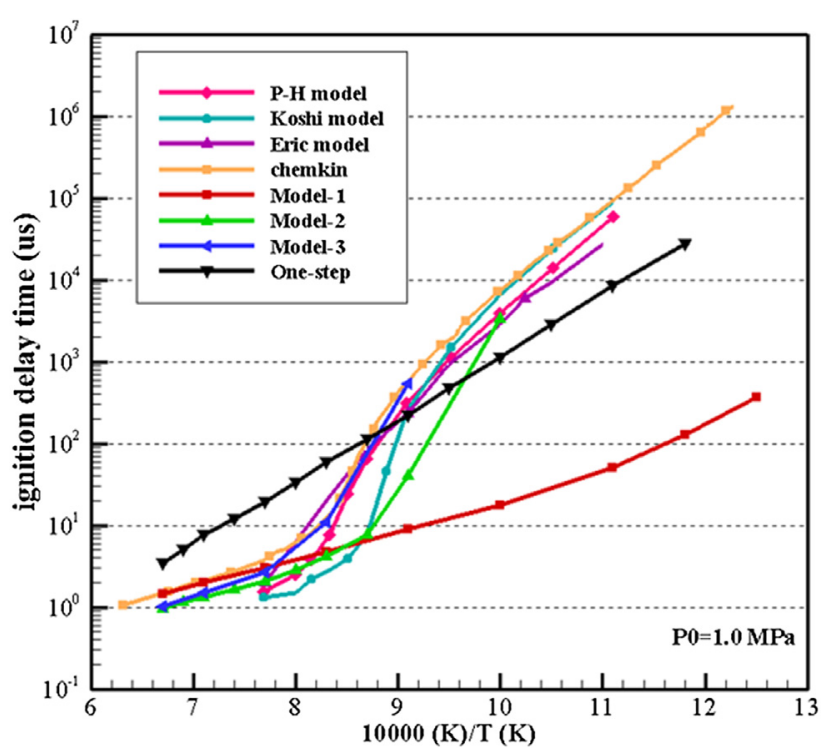

Fig. 4 - Comparison of ignition delay times predicted by different chemical reaction models at $1.0 \mathrm{MPa}$.

with initial pressures. That means it has the same ignition delay time at different initial pressures. The second difference is that its ignition delay time is almost linearly proportional to the reciprocal of initial temperature under the logarithmic coordinate system without any transition-temperature. This means that one-step overall model may not predict the correct deflagration to detonation transition.

Cellular structures of stoichiometric $\mathrm{H}_{2}$-Air mixture are numerically simulated by using three detailed models and the one-step model with initial pressure $\mathrm{P}_{0}=0.1 \mathrm{MPa}$ and initial temperature $\mathrm{T}_{0}=300 \mathrm{~K}$. The uniform mesh sizes are $\Delta \mathrm{x}=\Delta \mathrm{y}=10 \mu \mathrm{m}$ or $\Delta \mathrm{x}=\Delta \mathrm{y}=20 \mu \mathrm{m}$ for different cases, respectively. The computational domain width $\mathrm{w}$ is $2.00 \mathrm{~mm}$ for detailed models, and $\mathrm{w}=4.00 \mathrm{~mm}, 8.00 \mathrm{~mm}$ and $16.00 \mathrm{~mm}$ for the overall one-step model.

Fig. 5 shows the cellular structures of three detailed models. The cell size $\lambda$ is defined as the average width of all the cells of the steady C-J detonation. The cell size $\lambda$ predicted by

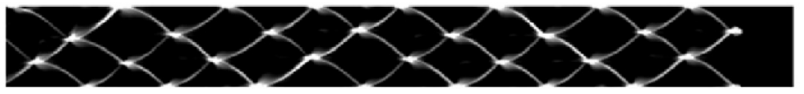

(1) Model-1: $\Delta x=\Delta y=10 \mu \mathrm{m}, \mathrm{w}=2.00 \mathrm{~mm}, \lambda=1.33 \mathrm{~mm}$

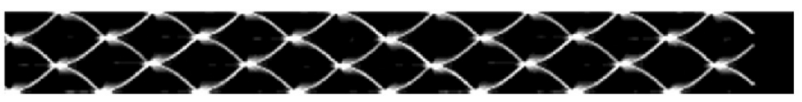

(2) Model-2: $\Delta x=\Delta y=10 \mu \mathrm{m}, \mathrm{w}=2.00 \mathrm{~mm}, \lambda=1.33 \mathrm{~mm}$

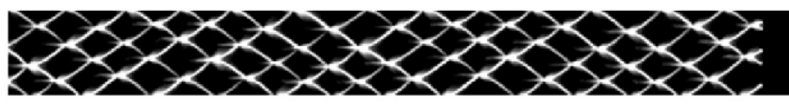

(3) Model-3: $\Delta x=\Delta y=10 \mu \mathrm{m}, w=2.00 \mathrm{~mm}, \lambda=0.80 \mathrm{~mm}$

Fig. 5 - Cellular structures simulated by three detailed models. 
Model- 1 is $1.33 \mathrm{~mm}, \lambda=1.33 \mathrm{~mm}$ for Model- 2 and $\lambda=0.80 \mathrm{~mm}$ for Model-3. However, the widths of the cells observed in the experiments are $8 \mathrm{~mm}-15 \mathrm{~mm}$ [33]. The numerical simulation result is about one order of magnitude smaller than the experimental results. In fact, for most of the chemical models, the cell sizes were at least more than 2 times smaller than experimental values [23].

Fig. 6 shows the pressure contours of detonation simulated by the one-step overall model and the cellular structures simulated by this model are shown in Fig. 7. Four kinds of domain sizes and grid scales are investigated in order to guarantee that the numerical results are independent of numerical algorithm. When $\mathrm{w}=4.00 \mathrm{~mm}$, we get half a cell in the direction perpendicular to the direction of the detonation propagation, and when $\mathrm{w}=8.00 \mathrm{~mm}$, we get a complete cell. When $\mathrm{w}$ is increased to $16.00 \mathrm{~mm}$, two complete cells appear in the computational domain. The numerical results are independent of domain sizes and grid scales. The average cell size is $6.0 \mathrm{~mm}-8.0 \mathrm{~mm}$ for all these three cases, which is consistent with experiment data quantitatively [33].

The average cell size predicted by the one-step model is bigger than those predicted by three detailed models. In addition, the ignition delay times predicted by the one-step model are longer than that predicted by detailed models at the same initial temperature and high pressure. From this study, we first find that the longer the ignition delay times are, the bigger the cell sizes are. The chemical reaction kinetics plays a very important role in the detonation cell size simulation. And in return, the cell size is a good representation of the chemical reaction kinetics. In the following part, we will discuss how the chemical reaction kinetics influences the detonation cell size.

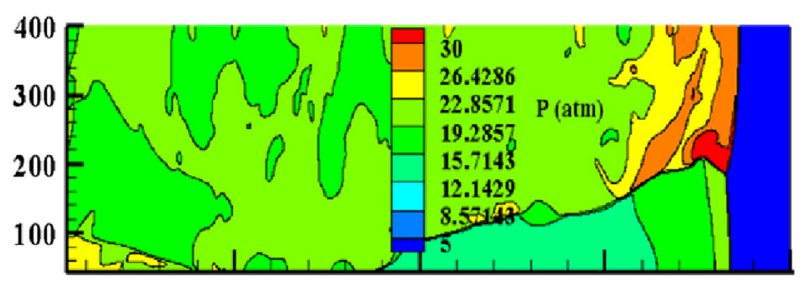

(1) $\Delta x=\Delta y=10 \mu \mathrm{m}, \mathrm{w}=4.00 \mathrm{~mm}$, one triple-wave point

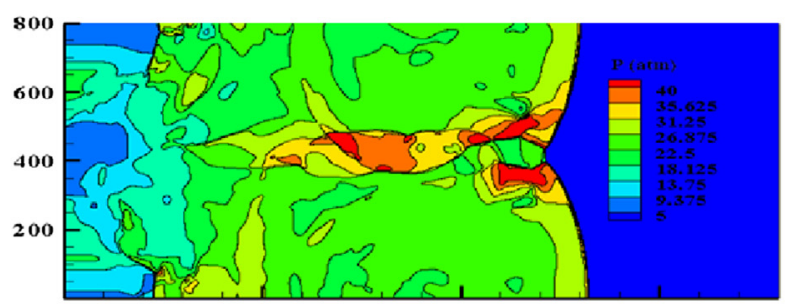

(2) $\Delta x=\Delta y=10 \mu \mathrm{m}, \mathrm{w}=8.00 \mathrm{~mm}$, one pair of triple-wave points

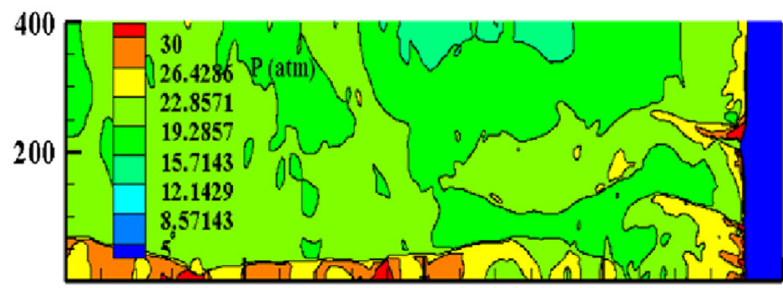

(3) $\Delta x=\Delta y=20 \mu \mathrm{m}, w=8.00 \mathrm{~mm}$, one pair of triple-wave points

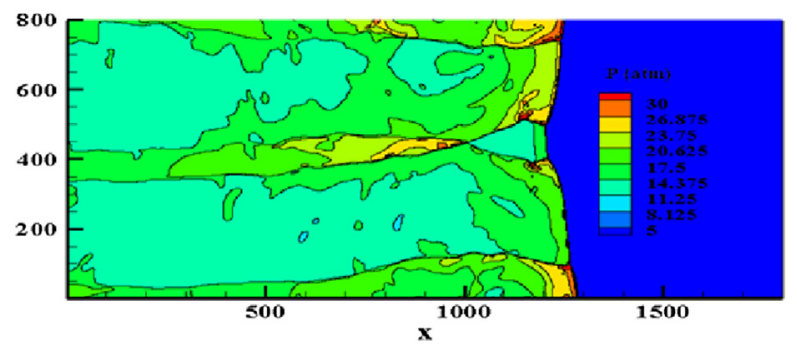

(4) $\Delta x=\Delta y=20 \mu \mathrm{m}, \mathrm{w}=16.00 \mathrm{~mm}$, two pairs of triple-wave points

Fig. 6 - Pressure contours of detonation front simulated by overall one-step model. 


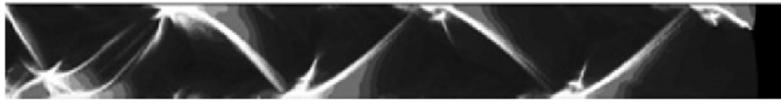

(1) $\Delta x=\Delta y=10 \mu \mathrm{m}, w=4.00 \mathrm{~mm}, \lambda=8.00 \mathrm{~mm}$

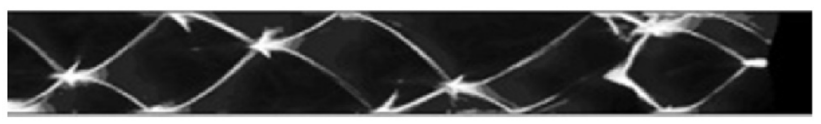

(2) $\Delta x=\Delta y=10 \mu \mathrm{m}, w=8.00 \mathrm{~mm}, \lambda=8.00 \mathrm{~mm}$

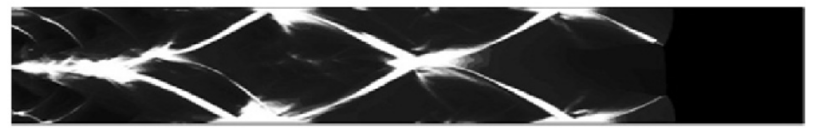

(3) $\Delta x=\Delta y=20 \mu \mathrm{m}, \mathrm{w}=8.00 \mathrm{~mm}, \lambda=8.00 \mathrm{~mm}$

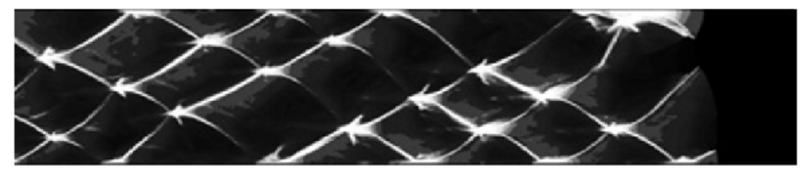

(4) $\Delta x=\Delta y=20 \mu \mathrm{m}, \mathrm{w}=16.00 \mathrm{~mm}, \lambda=8.00 \mathrm{~mm}$

Fig. 7 - Cellular structures simulated by the one-step model.

When the detonation propagates, the trajectories of tripleshock points produce the cellular structures. The period of the movement of triple-shock point is defined as the duration from the first collision of a pair of triple-shock point to the next collision of them in this study. According to this definition, a complete cell is produced in two complete periods of a pair of triple-shock point. The period of triple-shock point is a characteristic time scale of shock dynamics.

Fig. 8 shows a sequent of the movement of three pairs of triple-shock point of Model-3 by means of cellular structures as an example. The detonation is propagating from left to right. The trajectories show the way that three pairs of tripleshock points passed. The interval of each frame is $0.5 \mu \mathrm{s}$. In the frame (a), the triple-shocks collide, and in the frame (d), two complete cells are produced for these triple-shock points. The red cycle shows the triple-wave points. We can find that at frame (d), two complete cells are produced in front of the red cycle. In this case, the period of triple-shock points is about $0.38 \mu \mathrm{s}$. In addition, the ignition delay time predicted by model- 1 at $1500 \mathrm{~K}$ and $2.5 \mathrm{MPa}$ is about $0.50 \mu \mathrm{s}$, which is close to the period of triple-shock points. The numerical results predicted by Model-1 and Model-2 also come to the same conclusion.

The movement of a pair of triple-shock point simulated by the overall one-step model is shown in Fig. 9. The interval of each frame is $1.0 \mu \mathrm{s}$. In this case, the cycle of this movement is about $3.5 \mu \mathrm{s}$. The ignition delay time of this model at $1500 \mathrm{~K}$ is $3.46 \mu \mathrm{s}$. The average movement period of triple-shock points is equal to the ignition delay time of gas in the induction zone behind the incident shock wave.

The numerical results are summarized in Table 1. From Table 1, we can find that the period of triple-shock points almost equals to average ignition delay time of the gas in the induction zone. The movement period of triple-shock point represents the shock dynamic of detonation. The ignition delay time is considered as the chemical reaction kinetics of detonation. The shock dynamics and chemical reaction are coupled by these two characteristic times, which maintains the self-sustained propagation of C-J detonation.

In addition, we also find that the transverse velocity of the triple-wave points is about half the $\mathrm{H}_{2}$-air detonation velocity of $1950 \mathrm{~m} / \mathrm{s}$. This speed is almost equal to the sound speed of the detonation products of about $1100 \mathrm{~m} / \mathrm{s}$, which is about $1 / 2 D_{\mathrm{CJ}}$. It is also very close to the sound speed of reactants in the inductions zone which is about $900 \mathrm{~m} / \mathrm{s}$. This means that the transverse wave is a weak shock wave of about M1.2 propagating in the induction zone transversely and burning the reactants in the induction zone which is preheated by the incident shock wave. The average speed of transverse wave being about $1 / 2 \quad D_{C j}$ also indicates that the acute angle of the detonation cell is about $60^{\circ}$, which is shown in Fig. 10.

From the above discussion, we can obtain an equation to estimate the width of the detonation cell size:

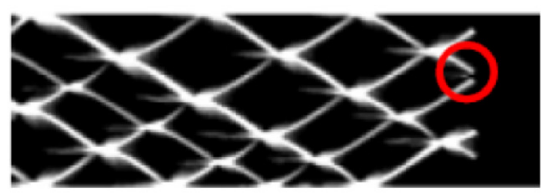

(a)

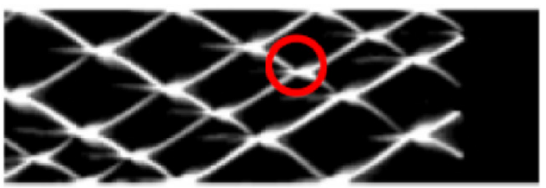

(c)

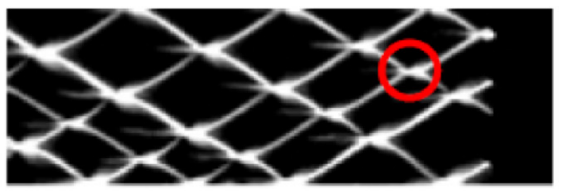

(b)

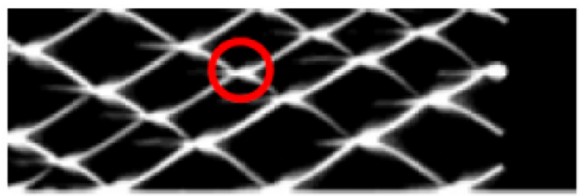

(d)

Fig. 8 - Movement of triple-shock points of Model-3 shown by cellular structures. 


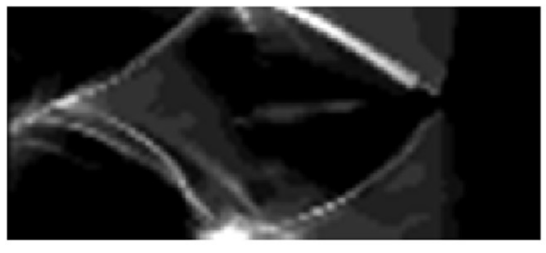

(a)

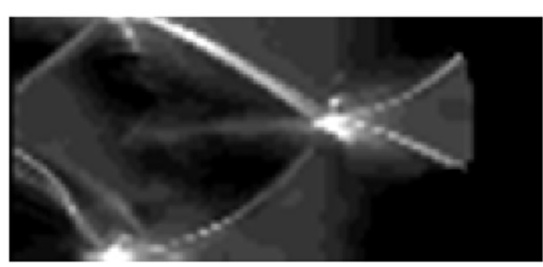

(c)

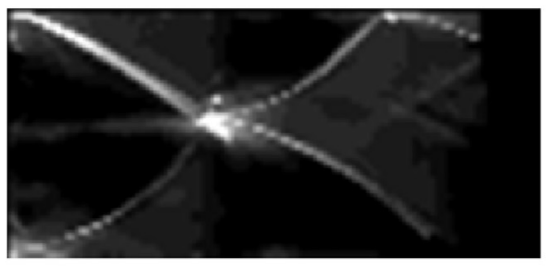

(e)

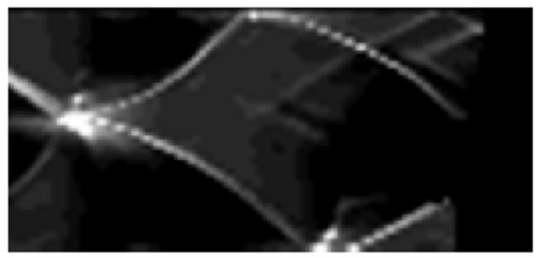

(g)

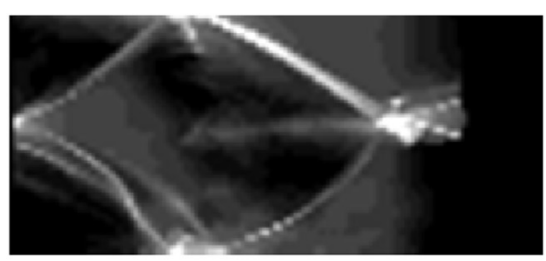

(b)

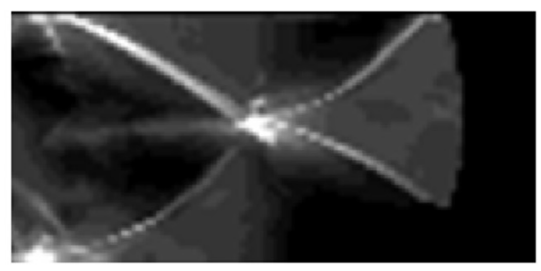

(d)

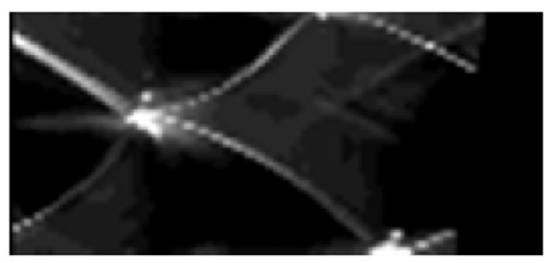

(f)

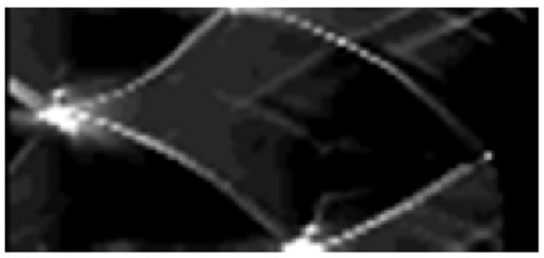

(h)

Fig. 9 - Movement of triple-shock points of one-step model showed by cellular structures.

\begin{tabular}{lcccc}
\hline Table $\mathbf{1}$ - Key parameters of $\mathbf{H}_{\mathbf{2}}$-Air detonations. \\
$\begin{array}{lccc}\text { Ignition delay time at 2.5 } \\
\mathrm{MPa} \text { and } 1500 \mathrm{~K}(\mu \mathrm{s})\end{array}$ & $\begin{array}{c}\text { Period of triple-shock } \\
\text { points }(\mu \mathrm{s})\end{array}$ & $\begin{array}{c}\text { Average cell size } \\
(\mathrm{mm})\end{array}$ & $\begin{array}{c}\text { Average speed of } \\
\text { transverse wave }(\mathrm{m} / \mathrm{s})\end{array}$ \\
\hline 1 & $0.65 \pm 0.1$ & $0.60 \pm 0.1$ & $1.33 \pm 0.1$ & $1108 \pm 30$ \\
2 & $0.52 \pm 0.1$ & $0.60 \pm 0.1$ & $1.33 \pm 0.1$ & $1108 \pm 30$ \\
3 & $0.50 \pm 0.1$ & $0.38 \pm 0.1$ & $0.80 \pm 0.1$ & $1052 \pm 30$ \\
One-step & $3.46 \pm 0.1$ & $3.50 \pm 0.1$ & $8.00 \pm 0.1$ & $1142 \pm 30$ \\
\hline
\end{tabular}




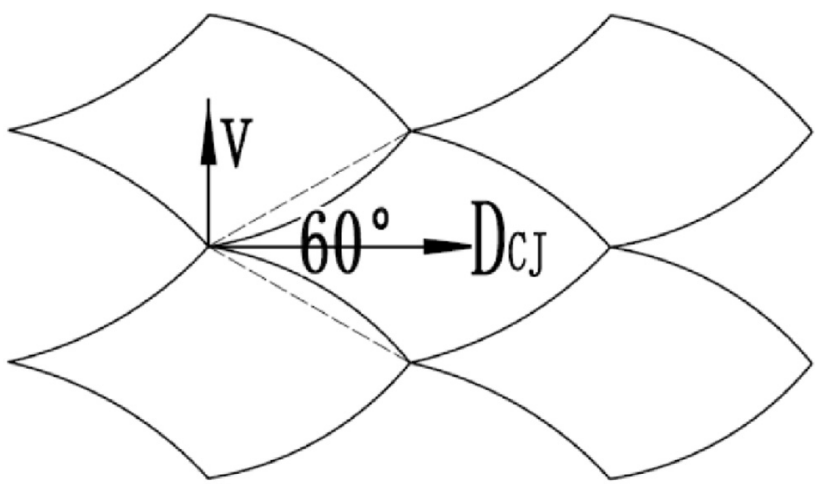

Fig. 10 - Diagram of detonation cells.

$\mathrm{W} \approx 2\left(\tau_{\text {ig }} \times \frac{1}{2} D_{C J}\right)=\tau_{\text {ig }} \times D_{C J}$

where, $\mathrm{W}$ is the average width of a detonation cell, $\tau_{\text {ig }}$ is the ignition delay time of the reactants under the conditions in the induction zone and $D_{C J}$ is the $C J$ detonation velocity.

\section{Conclusions}

In this paper, two-dimensional numerical simulations were conducted to study the key mechanism of self-sustained $\mathrm{H}_{2}$ Air detonation. Four detonation models were used, one is a modified one-step overall model and the other three are detailed chemical reaction kinetic models. The numerical results show that different chemical kinetic models have different ignition delay times and the differences are even more than one-order. The ignition delay time in the induction zone is a very important parameter which controls the movement of triple-shock points. The longer the ignition delay time is, the bigger the cell size will be. The average ignition delay time in the induction zone equals to the average period of triple-shock point movement. The shock dynamics and chemical reaction kinetics of gaseous detonation is closely coupled by these two important characteristic time scales, which keeps the self-sustained propagation of detonation.

\section{R E F E R E N C E S}

[1] Lee JHS. The detonation phenomenon. McGill University; 2008.

[2] Ng HD, Ju Y, Lee JHS. Assessment of detonation hazards in high-pressure hydrogen storage from chemical sensitivity analysis. Int J Hydrogen Energy 2007;32:93-9.

[3] Petukhov VA, Naboko IM, Fortov VE. Explosion hazard of hydrogen-air mixtures in the large volumes. Int J Hydrogen Energy 2009;34:5924-31.

[4] Soury Hossein, Mazaheri Kiumars. Utilizing unsteady curved detonation analysis and detailed kinetics to study the direct initiation of detonation in $\mathrm{H}_{2}-\mathrm{O}_{2}$ and $\mathrm{H}_{2}-$ Air mixtures. Int $\mathrm{J}$ Hydrogen Energy 2009;34:9847-56.
[5] Roya GD, Frolov SM, Borisov AA, Netzer DW. Pulse detonation propulsion: challenges, current status, and future perspective. Prog Energy Combust Sci 2004;30:545-672.

[6] Jiang ZL, Teng HH. Research on some fundamental problems of the universal framework for regular gaseous detonation initiation and propagation (in Chinese). Sci Sin-Phys Mech Astron 2012;42:421-35.

[7] Choi JY, Ma FH, Yang V. Some numerical issues on simulation of detonation cell structures. Combust Explos Shock Waves 2008;44:560-78.

[8] Oran ES, Boris JP, Young T, et al. Numerical simulations of detonations in hydrogen-air and methane-air mixtures. Eighteenth Symp Int Combust 1981;18:1641-9.

[9] Westbrook CK, Urtiew PA. Chemical kinetic prediction of critical parameters in gaseous detonations. Nineteenth Symposium Int Combust 1982;19:621-3.

[10] Shepherd JE. Chemical kinetics of hydrogen-air-diluent detonations. Prog Astronaut Aeronaut 1986;106:263-93.

[11] Kumar RK. Detonation cell width in hydrogen-oxygendiluent mixtures. Combust Flame 1990;80:157-69.

[12] Gamezo VN, Desbordes D, Oran ES. Formation and evolution of two-dimensional cellular detonations. Combust Flame 1999;116:154-65.

[13] Gamezo VN, Desbordes D, Oran ES. Two-dimensional reactive flow dynamics in cellular detonation waves. Shock Waves 1999;9:11-7.

[14] Trotsyuk AV. Numerical simulation of the structure of twodimensional gaseous detonation of an $\mathrm{H}_{2}-\mathrm{O}_{2}$ - $\mathrm{Ar}$ mixture. Combust Explos Shock Waves 1999;35:93-103.

[15] Sharpe GJ, Quirk JJ. Nonlinear cellular dynamics of the idealized detonation model: regular cells. Combust Theory Model 2007;12:1-21.

[16] Austin JM, Pintgen F, Shepherd JE. Reaction zones in highly unstable detonations. Proc Combust Inst 2005;30:1849-57.

[17] Pintgen F, Eckett CA, Austin JM, et al. Direct observations of reaction zone structure in propagating detonations. Combust Flame 2003;133:211-29.

[18] Sharpe GJ. Transverse waves in numerical simulations of cellular detonations. J Fluid Mech 2001;447:31-51.

[19] Oran ES, Weber JW, Stefaniw EI, et al. A numerical study of a two-dimensional $\mathrm{H}_{2}-\mathrm{O}_{2}$ - $\mathrm{Ar}$ detonation using a detailed chemical reaction model. Combust Flame 1998;113:147-63.

[20] Shchelkin KI, Troshin YK. Gas dynamics of detonations. Moscow: Izd. Akad. Nauk SSSR; 1963.

[21] Gavrikov AI, Efimenko AA, Dorofeev SB. A model for detonation cell size prediction from chemical kinetics. Combust Flame 2000;120:19-33.

[22] Eaton R, Zhang B, Bergthorson JM, et al. Measurement and chemical kinetic model predictions of detonation cell size in methanol-oxygen mixtures. Shock Waves 2012;22:173-8.

[23] Taylor BD, Kessler DA, Gamezo VN, et al. Numerical simulations of hydrogen detonations with detailed chemical kinetics. Proc Combust Inst 2013;34:2009-16.

[24] Burke MP, Chaos M, Ju YG, et al. Comprehensive $\mathrm{H}_{2}-\mathrm{O}_{2}$ kinetic model for high-pressure combustion. Int J Chem Kinet 2012;44:444-74.

[25] Li TW. Applications of finite spectral method and numerical simulations of one/two dimensional detonations. Peking University; 2004. Ph.D thesis (in Chinese).

[26] Teng HH. Investigation on some basic problems in the gaseous detonation initiation and propagation mechanisms. Chinese Academy of Sciences; 2008. Institute of Mechanics, Ph.D thesis (in Chinese).

[27] Liu YF, Jiang ZL. Study on the chemical reaction kinetics of detonation models (in Chinese). Sci Sin-Phys Mech Astron 2011;41:1296-306. 
[28] Zhang W, Liu YF, Jiang ZL. Study on the relationship between ignition delay time and gaseous detonation cell size (in Chinese). Chin J Theor Appl Mech 2014;46:977-81.

[29] Liu YF, Jiang ZL. Reconsideration on the role of the specific heat ratio in Arrhenius Law applications. Acta Mech Sin 2008;24:261-6.

[30] Slack MW. Rate coefficient for $\mathrm{H}+\mathrm{O}_{2}+\mathrm{M}=\mathrm{HO}_{2}+\mathrm{M}$ evaluated from shock tube measurements of induction times. Combust Flame 1977;28:241-9.
[31] Bhaskaran KA, Gupta MC, Just TH. Shock tube study of the effect of unsymmetrical dimethyl hydrazine on the ignition characteristics of hydrogen-air mixtures. Combust Flame 1973;21:45-8.

[32] Sharpe GJ, Short M. Detonation ignition from a temperature gradient for a two-step chain-branching kinetics model. J Fluid Mech 2003;476:267-92.

[33] Shepherd JE. Detonation database. Techn ical Report FM97-8, GALCIT. July 1997. 